\title{
Revisiting the Relationship between Poverty and Environmental Sustainability in Sub-Saharan African Countries using Dynamic Econometric Models
}

\author{
Owusu Samuel Mensah ${ }^{1}$ \\ Chen Jianlin ${ }^{2}$ \\ Fu Chuambo ${ }^{3}$ \\ Hu Qio ${ }^{4}$
}

${ }^{1,2,3,4}$ School of Business, Jinggangshan University, Qingyuan District, Ji'an City, Jiangxi Province, China.

'Email: omensju15@yahoo.com

( Corresponding Author)

\begin{abstract}
Sustainable development remains an important issue in the quest to achieve a safe and a better world. The expansion of the 8 millennium development goals into the 17 sustainable development goals is a testament of the conscious desire to improve the human environment to ensure better quality of life for its citizens. This study assembles a collection of four sophisticated econometric models to determine the impact of poverty and other variables on two indicators of environmental sustainability. Beside, economic development, the study confirmed the negative impact of poverty on both indicators of sustainable development. The results prove that poverty in sub-Saharan Africa is a threat to environmental quality and its consequential challenges. The call to promote environmentally responsible behaviours should not be focused on developed countries alone. Poverty is also associated with high levels of pollution and poor countries including countries in sub-Saharan Africa contributes must equally restrategise for effective environmental goals. The study further discloses that poverty is one of the strongest factors that affect environmental sustainability. This observation is not a contradiction to the well-established fact that prosperity or economic growth is a major precursor of unsustainable environment. On the contrary the evidence in this paper amplifies a consequence of a social crisis if they fester at both ends. In one breath, whereas economic growth or economic prosperity can compromise the quality of the environment.

In conclusion, this result implies that African countries in their pursuit of economic growth, education and effective healthcare to ameliorate poverty must incorporate other aggressive strategies to hasten poverty reduction.
\end{abstract}

Keywords: Relationship, Environment, Sustainability, Dynamic ordinary least square regression, Poverty, Sub-Saharan Africa.

Citation | Owusu Samuel Mensah; Chen Jianlin; Fu Chuambo; Hu Qio (2021). Revisiting the Relationship between Poverty and Environmental Sustainability in Sub-Saharan African Countries using Dynamic Econometric Models. Economy, 8(2): 16-28. History:

Received: 2 September 2021

Revised: 30 September 2021

Accepted: 22 October 2021

Published: 15 November 2021

Licensed: This work is licensed under a Creative Commons

Attribution 3.0 License $(\mathrm{cc})$ )

Publisher: Asian Online Journal Publishing Group
Acknowledgement: All authors contributed to the conception and design of the study.

Funding: The study is funded by the National Self-finance Fund Project "Based on the Dual Network Embedding of Small and Micro Enterprises' Life Cycle Trap Breakthrough Mechanism and Path Research"Item Number: Cycle Trap Breakthrough Mechanism and Path Research Item Number: 71563022

Competing Interests: The authors declare that they have no conflict of interests.

Transparency: The authors confirm that the manuscript is an honest, accurate, and transparent account of the study was reported; that no vital features of the study have been omitted; and that any discrepancies from the study as planned have been explained.

Ethical: This study follows all ethical practices during writing.

\section{Contents}

1. Introduction

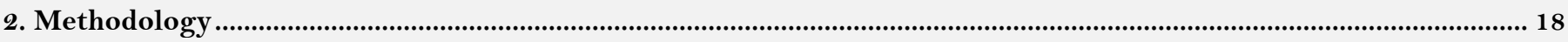

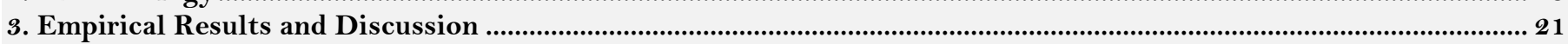

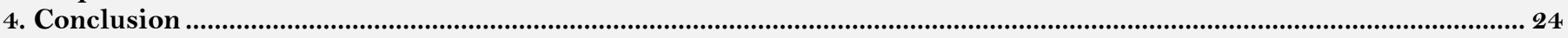

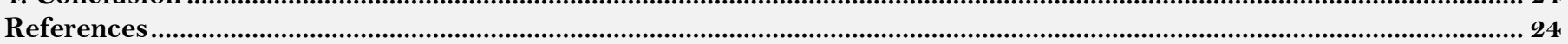




\section{Contribution of this paper to the literature}

This study contributes to existing literature by determining the impact of poverty and other variables on two indicators of environmental sustainability.

\section{Introduction}

Globally, there is the growing concern that environmental quality is depleting at an alarming rate and has even reached unsustainable levels. With escalating scarcity of clean air, drying water bodies, shifting climates, and destructions of entire ecosystems, Asongu, Agboola, Alola, and Bekun (2020) predicts an unprecedented global environmental calamity if extraordinary and globally-coordinated measures are not implemented in time to arrest the spiralling situation. Increasingly, a number of well-established literature links economic growth and environmental pollution and this gratuitous environmental destruction nexus (Adedoyin, Alola, \& Bekun, 2020).

A significant number of the available research materials provide empirical evidence to support the claims that economically advanced countries are largely responsible for the continuous decline in environmental quality (Joshua \& Bekun, 2020). The reason is that increasing environmental pollution may be a negative spill-over of the overbearing pursuit of economic growth through unsustainable means (Joshua \& Bekun, 2020). Expectedly, most of the discontent with the provisions of the 2015 Paris Accord and its predecessor Kyoto Protocol, have come from developed countries such as USA, China, Japan etc that emits high carbon dioxide into the atmosphere (Adekunle, 2020). These countries believe that some of the provisions in the protocol are unfairly targeted at them. The protocols are believed to impose unworkable and unrealistic carbon reduction targets on developed economies with recourse to the economic responsibility to less developed economies (Khan, Zhang, Kumar, Zavadskas, \& Streimikiene, 2020).

In the extant literature, four main theories have emerged that links economic growth to environmental pollution. These are an inverted U-shaped relationship between economic growth and environmental pollution (Bekun, Yalçiner, Etokakpan, \& Alola, 2020), a monotonically increasing relationship economic growth and environmental pollution (Eluwole, Saint Akadiri, Alola, \& Etokakpan, 2020), a U-shaped relationship (Khan, Yu, Sharif, \& Golpîra, 2020) economic growth and environmental pollution and an N-shaped relationship economic growth and environmental pollution (Ibrahim \& Alola, 2020).

Theoretically, several theories that explain the interplay between economic growth and environmental pollution emerged as early as the 1970s but Grossman and Krueger's (Demissew Beyene \& Kotosz, 2020) Environmental Kuznet Curve (EKC) theory laid the foundation of modern advances in the subject. This same position is well explained in the later work of Panayotou (Lan, 2021). The Environmental Kuznet Curve theory indicates that an inverted u-shaped relationship exists between the level of income and the environmental degradation and it evolves in stages. At the onset of economic growth, the increase in industrial activities contributes to high environmental deterioration (Asongu \& Odhiambo, 2021). The deterioration at this stage occurs due to increase in energy intensive production that quickens the emission of pollutants. At the second stage of industrialisation, the service and technology-intensive knowledge-based industry begins to develop. At this point, the decline in environmental degradation begin to slow down correspondingly due to the changes in production, environmental awareness and the promulgation of stricter environmental regulations (Kirikkaleli \& Sowah, 2020).

Thus, the EKC theory implies that composition effect, scale effect and technique effect are the main channels through which environmental welfare is affected by economic growth. In this theory it is argued that growth in economic scale leads to proportional growth in environmental pollution whiles changes in the structure of the industry leads to a reduction in the intensity of the pollution. Additionally, Grossman and Krueger (Usman, Akadiri, \& Adeshola, 2020) suggest that economic growth inspires technological progress which brings in enhanced, and cleaner technologies to replace obsolete ones to further improve the quality of the environment. Related studies on economic growth and environmental pollution have also examined the reverse effect of environmental pollution on economic growth.

However, an emerging strand of literature that is receiving significant academic curiosity is the linkages between economic poverty and environmental pollution. According to Baloch, Khan, and Ulucak (2020) academic interest that establishes the relationship between poverty and environmental pollution dates back to the early 1980 s but this area of academic specialisation failed to elicit the needed research interest and global interest due to the overbearing effect of economic growth on environmental pollution. Secondly, several groups have emerged at both national and international level to highlight, protest and finance the advocacy on the effect of economic growth on environmental pollution but this is not the case with how poverty affects environmental pollution. The imbalance in studies in this regard is explained in Baloch, Khan, Ulucak, and Ahmad (2020) when they content that even though global effort has been concentrated on how to mitigate environmental stress through sustainable economic growth, poverty also plays a major role in environmental degradation and health related quality of life across the globe. This may have influenced the millennium fathers to declare the need to reduce absolute poverty as the first of both the millennium development goal (MDGs) and the successor Sustainable Development Goals (SDGs).

The objective of these goals is to alleviate absolute poverty by 2030. This bias in studies about environmental pollution explains the paucity of studies on Africa's contribution to environmental pollution globally as the continent is deprived of the large industries that emit high carbon dioxide into the atmosphere. Yet poverty can be a major source of environmental pollution and its reduction can further accentuate effort to reduce environmentalled calamities in Africa.

Generally, literature on African growth and development and poverty reduction is extensive; however, few have attempted to establish the link between public investment and poverty reduction in Sub-Saharan Africa. According to World Bank (2015) Africa for the past two decades has seen a tremendous increase in its economy recording an annual growth rate of 4.5 percent, however, translating these economic gains into improving the wellbeing of the people has been a major concern. Sub-Saharan Africa in 2015 had 27 out of 28 poorest countries living in an absolute poverty in the world and the average poverty was at 41 percent in sub-Saharan Africa as 
compare to 13 percent in the other regions in 2015 (World Bank Report, 2018b). The sub-region continues to record high population growth, high level of poverty, and the weak economic situation coupled with poor management of the Covid-19 pandemic is deteriorating and worsening socioeconomic conditions of the people. The continent saw its population doubled between 1990 and 2015 , with significant number of people living on less than $\$ 1.90$ a day (World Bank Report, 2018a). Sub-Saharan Africa is among the worst regions in the world with high rate of poverty and their income per capita or GDP per capita fall toward the bottom of list of countries globally (Adeyeye, Adebayo-Oyetoro, \& Tiamiyu, 2017; Baloch et al., 2020). Poverty is classified as one of the greatest challenges in sub-region and its eradication remains an integral part of the developmental agendas (Fombad, 2018).

In the opinion of Jan and Shah (2020) poverty affects environmental quality through deforestation and other negative farming practices. The forest is the main source of fresh and clean air and water to enhance the quality of the human environment. Forest act as sinking hoes to reduce the drastic effect of climate change on human health. Conversely, an increase in deforestation compromises how forests play this role. Many impoverished communities are aware of the errant and harmful effect of deforestation but have limited choices.

Poor communities purposely raze down forest lands to make space for agricultural activities, animal grazing and obtain wood for fuel. Through lumbering, quarrying, extensive road construction into regions that were once almost inaccessible, building and upgrading of roads into forests along with other destructive patterns further spirals the environmental quality downwards. Deforestation can result in more carbon dioxide being released into the atmosphere. That is because trees take in carbon dioxide from the air for photosynthesis, and carbon is locked chemically in their wood. When trees are burned, this carbon returns to the atmosphere as carbon dioxide. With fewer trees around to take in the carbon dioxide, this greenhouse gas accumulates in the atmosphere and accelerates global warming.

According to Radosavljevic, Haider, Lade, and Schlüter (2020) due to poor environmental and sanitation planning at both government and domestic level, environmental pollution persists in several underdeveloped economies. In some of these countries human and other household waste are directly dumped into water bodies. These may be the same sources of farming and livestock production that increases the chances of pollution. In relation to air pollution, Hirons (2020) explains that poor communities lack knowledge about proper production techniques hence employ very crude methods which may compromise the quality of air. In essence, waste disposal is one of the major challenges associated with poverty. Poor communities lack efficient waste disposal systems which affect the health of the individuals and the health of their environment. Mnini and Ramoroka (2020) also explain that extreme poverty is strongly correlated with high birth rates.

The resulting population boom in poorer communities is an additional burden on the environment. This is because more people will have to extract the maximum benefit from the limited primary resources available. For example, in some countries, water and air quality has reduced significantly due to the activities of small-scale miners as pertain in the case in Ghana. The effect of poverty on carbon emission is specifically addressed in the work of Baloch et al. (2020). Their study specifically explored the linkages between income inequality, poverty, and carbon dioxide (CO2) emissions for the 40 Sub-Saharan African countries over the period 2010 - 2016. Using the Driscoll Kray regression estimator, this study revealed that suggest income inequality was positively related to $\mathrm{CO}_{2}$ emissions but negatively related to environmental pollution in Sub-Saharan African countries. This together with related studies truly affirms the influence of poverty as a major cause of environmental pollution. Thus, if poverty is eradicated, it may minimize several environmental problems. That notwithstanding, the genealogy of the relationship between poverty and environmental sustainability is highly convoluted (Aust, Morais, \& Pinto, $2020)$.

To this end, previous efforts to measure the precision of this relationship have often ended with inconclusive or conflicting outcomes. For example, one school of thought suggests that the linear causal link between poverty and environmental quality or sustainability is too simplistic. Instead, the nexus is governed by a complex web of factors. There are institutional and market failures factors, conflicts between different agents (income groups) and other compounding factors. This paper explores the relationship between poverty and environmental sustainability in sub-Saharan Africa. The rest of the paper is arranged as follows. Section 2 provides further information on poverty in the sub-region. Section 3 provides data and the empirical methodology. Section 4 presents the empirical findings. Section 5 concludes with suggestions

\section{Methodology}

This paper employs (Stock \& Watson, 1993) dynamic ordinary least square regression (DOLS), the two-staged least square regression model and dynamic panel model using system-GMM to provide comprehensive understanding of the relationship between poverty and environmental sustainability in sub-Saharan Africa (Ullah, Awan, \& ul Hasan, 2020). The DOLS is used because it allows integration of variables of alternative orders (in this sense, a higher order of integration). It also reduces possible simultaneity amongst the regressors. The two-staged least square regression model is also applied in this study as the regressor is contemporaneously correlated with the equation's disturbance and consequently, the OLS estimates will be bias and inconsistent. The system-GMM proposed by Arellano (2003) and developed by Blundell and Bond (1998) is adopted for the study due as it is widely used and affirmed in similar studies with robustness of inferences The model is formulated as follows;

\subsection{Panel Causality Test}

This paper adopted the panel causality test by Dumitrescu and Hurlin (2012) to understand the causal relationship among the variables. This form of test takes into consideration two heterogeneity classifications. Following, Arellano (2003) the equation is formulated as follows:

$$
y_{i, t}=\eta_{i}+\sum_{h-1}^{H} \chi_{i}^{(h)} \chi_{i, t-h}+\sum_{h-1}^{H} \rho_{i}^{(h)} \chi_{i, t-h}+\varepsilon_{i, t} \quad i=1,2, \ldots \ldots . N: t=1,2, \ldots \ldots, T
$$


From the equation above, we represented the two stationary variables used in the study by $x$ and $y$ as $N$ individuals in $T$ periods. $\rho_{i}=\left(\rho_{i}^{(1)}, \ldots, \rho_{i}^{(h)}\right)$ along with individual effects $\eta_{i}$ are fixed in the time dimension specification. Moreover, it is believed that the lag orders of $H$ are homogenous for the complete cross-section of the panel data of the study. Besides the $\chi_{i}^{(h)}$ and $\rho_{i}^{(h)}$, which are autoregressive parameters and the regression coefficients are permitted to be different cross groups, Equation 1.

The test approach has the assumption that the null hypothesis have no causal relationship for the units available $(x$ and $y)$ in the panel data. If, however, the hypothesis $\left(H_{o}\right)$ is rejected the study can conclude that there is causal relationship between the $x$ and $y$ variables. The $x$ and $y$ can also be used to measure the bidirectional causality, which is also termed as feedback impacts. The assumption is referred to as Homogeneous Non-Causality (HENC) hypothesis, which can be explained as:

$H_{0}: \rho_{i}=0, \Omega_{i}=1, \ldots . D$

Under the alternative hypothesis, which is Heterogeneous Non-Causality (HENC) hypothesis only two categories of cross section units are allowed. The study further takes into consideration the heterogeneous panelised data, which constitute fixed coefficients and the alternative hypothesis is therefore, presented as follows:

$$
\begin{aligned}
& H_{1}: \rho_{i}=0, \Omega \Omega_{i}=1, \ldots D \\
& H_{1}: \rho_{i} \neq 0, \Omega_{i}=D_{1}+1, \ldots . D
\end{aligned}
$$

There is the assumption that $\rho_{i}$ comes in divers ways across groups in addition to the $D_{1}$, where $\mathrm{D}$ represents the each procedure without causal relationship between the $x$ and $y$ variables. From the hypothesis above, it is assumed that the $D_{1}$ cannot be identified, however it allows the condition $0 \leq D_{1} / D>1$.

The study, therefore proposed the statistics $W_{D, T}^{H N C}$ linked to null Homogenous Non-Causality as bellow:

$$
w_{D, T}^{H N C}=\frac{1}{D} \cdot \sum_{t=1}^{D} W_{i, T}
$$

From the Equation 2, the $W_{i, T}$ represents the individual Wald Statistics as regards to the $i^{\text {th }}$ cross-section unit to have a relationship with the test hypothesis $H_{0}: \rho_{i}=0$ on individual bases, Equation 2.

Let $V_{1}=\left[\aleph: Y_{i}: X_{i}\right]$ represent the $(T, 2 H-1)$ matrix, in which $\aleph$ shows a $(T, 1)$ unit vector and $Y_{i}=\left[y_{i}^{1}: y_{i}^{2}: \ldots . .: y_{i}^{H}\right], X_{i}=\left[x_{i}^{1}: x_{i}^{2}: \ldots . . x^{H}\right] \cdot \varpi_{i}=\left(\eta_{i} \chi_{i}^{\prime} \rho_{i}^{\prime}\right)$ illustrates vectors of parameters of the framework and represented $F=\left[0: 1_{H}\right]$ be a $[H, 2 H+1]$ matrix.

According to the module, for every $i=1, \ldots . D$, the Wald statistics make an estimation of $W_{i, T}$ to match the individual test $H_{0}: \rho_{i}=0$. Thus is can be formulated as follow:

$$
W_{i, T}=\ddot{\varpi}_{i}^{\prime} F^{\prime}\left[b_{i}^{\prime 2} F\left(V_{i}^{\prime} N_{i}\right)^{-1} V^{\prime}\right]^{-1} V \ddot{\varpi}_{i}
$$

With regards to the null hypothesis of non-causality, the Wild statistic value is linked up to the a chi-squared distribution that has $\mathrm{H}$ degrees of freedom for $T \rightarrow \partial$, Equation 3.

$W_{i, T} \rightarrow \beta^{2}(H), \Omega_{i}=1 \ldots \ldots . D$

$V_{D, T}^{H N C}=\sqrt{\frac{D}{2 H}}\left(W_{D, T}^{H N C}-K\right) \rightarrow D(0,1)$

The standardized test statistics estimate $V_{D, T}^{H N C}$ for $T, D \rightarrow \partial$ is presented as:

The study further presents the standardized test estimate $V_{D}^{H N C}$ for fixed $\mathrm{T}$ samples outlined as:

$$
V_{D}^{H N C}=\sqrt{\frac{D}{2 H}} \cdot x \frac{(T-2 H-5)}{(T-H-3)} \cdot x\left[\frac{T-2 H-3}{T-2 H-1} \cdot W_{D, T}^{H N C}-H\right] \rightarrow D(0,1)
$$

The Equation 4 and 5 can be simply illustrated as $W_{D, T}^{H N C}=(1 / D) \sum_{i-1}^{D} W_{i T}$.

In short the statistics values shown above the Granger causality process output represents the values for $\mathrm{W}(\mathrm{W}$-bar $), \mathrm{Z}(\mathrm{Z}$-bar $)$, and then

$W(W-$ bar $), Z(Z$ - bar $), Z(Z-$ bar $)$, and $Z(Z$-bar tilde $)$.

$$
\begin{aligned}
& f\left(x_{i t^{\prime}} A, Y\right)=\left(\operatorname{Ln}(Y-A)-\operatorname{Ln}\left(x_{i t}-A\right)\right) / \operatorname{Ln}(Y-A) \\
& f\left(x_{i t^{\prime}} x_{i t-1}, A, Y\right)=f\left(x_{i t^{\prime}} A, Y\right)-f\left(x_{i t-1}, A, Y\right)
\end{aligned}
$$

Where $A$ is the highest possible value and $B$ is the lowest possible value of indicator $x$ for country $i$ at time $t$ and Ln represents the natural logarithm, Equation 5.

\subsection{Generalised Methods of Moments}

This paper adopted Generalised Methods of Moments (GMM) to investigate the dynamism, Heteroskedasticity and endogeneity found in the regression models. Following Dumitrescu and Hurlin (2012) the paper formulated two regression models as follows: 


$$
\begin{gathered}
E S T_{i t}=\beta_{1}+\beta_{2} E S D_{i t-1}+\beta_{3} P O V_{i t}+\beta_{4} F I N_{i t}+\beta_{5} I N S_{i t}+\beta_{6} E D U_{i t}+\beta_{7} U R B_{i t}+\beta_{8} T O P_{i t}+\varepsilon_{i t}(6) \\
E S D_{i t}=\beta_{1}+\beta_{2} E S D_{i t-1}+\beta_{3} P O V_{i t}+\beta_{4} F I N_{i t}+\beta_{5} I N S_{i t}+\beta_{6} E D U_{i t}+\beta_{7} U R B_{i t}+\beta_{8} T O P_{i t}+\varepsilon_{i t}
\end{gathered}
$$

where, ${ }^{i}$ denotes the country ${ }^{i=1, \ldots N}$ while ${ }^{t}$ represents the time $E S T_{i t}$ and $E S D_{i t}$ are two different indicants of the lagged dependent factor of environmental sustainability, whereas POV is the proxy for poverty, Equation 6 and 7. FIN represents financial development whiles INS is the proxy for institutional quality. EDU is the proxy for government expenditure on education (\% of GDP), while URB measures Urbanization and TOP is an indicator of Openness to Trade. Oseni (2016) further argues that including lagged dependent variables as an independent violate "orthogonality assumption", however, when the coefficient of the interest are finite-dimensional. The GMM estimators are known to be consistent, asymptotically normal, and efficient in the class of all estimators that do not use extra information aside from that contained in the moment conditions (Edrees, 2015).

\subsection{Data Source and Variable Specification}

The study adopts a cross-country panel data of 15 sub-Saharan African (SSA) countries with related economic and poverty indicators. To enable comparative analysis based on regions, the countries were further sub-divided into the four regions with SSA. The countries selected from western SSA were Ghana, Senegal, Côte d'Ivoire, and Benin while Angola, Cameroon, and DR Congo were selected from Central African region. On the other hand, Ethiopia, Kenya, Rwanda, and Uganda were selected from Eastern Africa whereas South Africa, Botswana, Namibia, Lesotho was selected from Southern Africa. The data span the period of 2009 and 2019 as they were those available at the time of the study. The entire data was selected from World Bank database, 2019. The reliability of the data was cross-checked with complementary data from other international and independent sources. The variables of study were carefully chosen to reflect previous analysis on the significant factors that affect environmental quality or sustainability. Table 1 shows the detailed description of variables.

Table-1. Variable definition and data source.

\begin{tabular}{l|l|l}
\hline Variables definitions & Operational definition & Data Source \\
\hline EST & $\begin{array}{l}\text { Adjusted Net Savings, excluding particulates emission damage. } \\
\text { (\%of GNI) }\end{array}$ & World Bank database \\
\hline ESD & $\begin{array}{l}\text { Forest Depletion is the product of unit resource rents and the } \\
\text { excess of round wood harvest over natural growth. Natural } \\
\text { Resources Depletion is the sum of net forest depletion, energy } \\
\text { depletion, and mineral depletion etc. }\end{array}$ & World Bank database \\
\hline POV & Poverty headcount ratio at $\$ 1.90 /$ a day (2011 PPP) & World Bank database \\
\hline FIN & $\begin{array}{l}\text { Financial Development (percentage of private sector share of } \\
\text { GDP) }\end{array}$ & World Bank database \\
\hline INS & $\begin{array}{l}\text { Institutional Quality (governance effectiveness and regulatory } \\
\text { quality index) }\end{array}$ & World Bank database \\
\hline EDU & Government expenditure on education, total (\% of GDP) & World Bank database \\
\hline URB & Urbanization (\% of urban population/Total Population) & World Bank database \\
\hline TOP & Openness to Trade $\%$ of import and export as \% of GDP) & World Bank database \\
\hline Notes: ${ }^{\mathrm{n}}$ Variables are converted into their natural logarithm to ensure normal distribution of data.
\end{tabular}

Notes: ${ }^{\mathrm{n}}$ Variables are converted into their natural logarithm to ensure normal distribution of data.

The extant literature presents a plethora of measures admitted as proxy for environmental sustainability or sustainable development. Researchers argue that the different measures are useful depending on the context of study. In this study, two measures of environmental sustainability were used and each of them was tested differently. Using the two measures of environmental sustainability is helpful as it enables the study to determine the impact of poverty on all aspects of environmental sustainable. The first measure of environmental sustainability (EST) is based on the adjusted net savings plus education expenditure and minus energy depletion, mineral depletion, net forest depletion, and carbon dioxide level. This measure of sustainable development was first introduced by Pearce and Atkinson (1998) as proxy for a weak sustainability ranking. This measure itself was an improvement of an earlier one introduced by Hartwick (1990).

In this model, it is assumed that income from non-renewable resources must be reinvested in renewable resources to maintain the ecological balance and social wellbeing. Pearce and Atkinson (1993) is the one that saves more than its combined depletion of natural resources and produced capital. A country is perceived to be on an unsustainable path if the value of this proxy is negative. Recent studies that has used this measure of sustainable development has been successfully used in Arrow, Dasgupta, Goulder, Mumford, and Oleson (2012); Blum, Ducoing, and McLaughlin (2017); Greasley et al. (2014), and have obtained robustness of inference.

The second proxy of environmental sustainability (ESD) is adopted from Ntow-Gyamfi, Bokpin, Aboagye, and Ackah (2020) which combine forest depletion, natural resource depletion, energy and mineral resources depletion, $\mathrm{CO}_{2}$ emissions and total greenhouse emissions. Since these variables are measured in different units (Ntow-Gyamfi et al., 2020). To standardize the measure and make it suitable for the estimation, the natural log of each indicant is taken. Since the index of environmental sustainability is made up of different variables, with different units of measurement, Kakwani, Wagstaff, and Van Doorslaer (1997) approach was used to reconstruct all into a unit free variable. The final unit free Environmental Sustainability index was constructed using the following steps. In the first place an achievement index was constructed for each variable. The formula for achievement index for the variables is mathematically expressed as;

$$
(x i t, B, T)=(\operatorname{Ln}(T-B)-\operatorname{Ln}(x i t-B)) / \operatorname{Ln}(T-B)
$$

where $T$ is the highest possible value and $B$ is the lowest possible value of indicator $x$ for country $i$ at time $t$ and $L n$ is the natural logarithm, Equation 8. An improvement index for indicator $x$ which shall later feed into the sustainability index is therefore given as:

$$
f(x i t, x i t-1, T, B)=f(x i t, T, B)-f(x i t-1, T, B)
$$


We then obtained the second index of sustainable development by taking the average of the improvement index of the sustainability variables explained above. With the result obtained from the equation above, a higher value indicates more sustainable environment, Equation 9.

Since the effect of poverty (POV) is the focus of this study, poverty is the first explanatory variable. Again many different measurement of poverty have emerged with context specific factors. According to Pezzey (2004) increasingly, the measurement of poverty keeps changing. While some people recommend a multidimensional approach that comprises social, economic, natural and socio-political factors, there are those that insist on using only economic wellbeing. This debate has intensified the emergence of both monetary and non-monetary poverty theories. Further, the extant literature is inconclusive as to whether relative or absolute poverty is the best definition of poverty. Based on the peculiarities of Sub-Saharan Africa, we measured poverty using the existing poverty headcount ratio at $\$ 1.90 /$ a day as which was proposed by the World Bank in 2011. This measures economic poverty by the percentage of the population that lives on less than $\$ 1.90$ a day at 2011 international prices.

The other explanatory variables include the financial development (FIN) and institutional quality (INS). Further, education (EDU), urbanization (URB), trade openness (TOP) are included as control variables based on previous established studies in other parts of the world. Exploring how these affect environmental sustainability in Sub-Saharan Africa is critical considering the number of uneducated persons that live in this part of the world.

It is the belief of the authors that increase in education must positively correspond to increase in eco-system awareness and environmentally responsible behaviour. Conversely an illiterate community will struggle to understand and appreciate the futuristic benefits of preserving the eco-system in preference for immediate benefit. Like the other variables, measuring education lends itself to several interpretations but this study measured education by the number of secondary school enrolment.

Financial development is measured by the percentage of private sector share of GDP whereas institutional quality is proxy by governance effectiveness and regulatory quality indexes. Urbanization is measured based on the percentage of urban population as proportion of the total population whiles trade openness is measured as the sum of imports and exports expressed as a percentage of GDP.

\section{Empirical Results and Discussion}

\subsection{Pre-Estimation Results}

The mean and median of the variables used for the study are presented in Table 2 below and fall within the maximum and minimum values. The results from Table 2 further shows that $60 \%$ of the variables are positively skewed, which include ESD, FIN, INS, EDU and TOP, and EST, POV and URB variables are negatively skewed. From Table 2 all the values of the kurtosis, including EST,ESD,FIN,POV,INS,EDU,URB and TOP reveal the leptokurtic nature of the variables used for the study (Oseni, 2016).

Table 2 further reports the values of the Jarque-Bera and their p-values of the coefficient less than 0.01, which means rejecting the null hypothesis of the normal distribution. The Jarque-Bera statistic is used to test whether a sequence follows a normal distribution. Furthermore, the correlation among the variables was tested to detect whether the variables used for the study have high multicollinearity among themselves in Table 3. Multicollinearity among variables occurs when the correlation coefficient results is more than 0.5.

Table 3 gives the results of the correlation coefficients among the independent variables used for the study. The results indicates the absence of any multicollinearity among the predictor variables.

\begin{tabular}{c|c|c|c|c|c|c|c|c}
\multicolumn{8}{c}{ Table-2. Descriptive statistics, normality test and correlation matrix. } \\
\hline Variables & EST & ESD & FIN & POV & INS & EDU & URB & TOP \\
\hline Mean & 1.7245 & 1.0453 & 21.58298 & 15.27824 & 21.58298 & 1.88263 & 72.37603 & 1.88263 \\
\hline Median & 10.7 & 1.9483 & 11.10415 & 10.7 & 11.10415 & 1.577535 & 5.047062 & 1.577535 \\
\hline Maximum & 32.7 & 6.3821 & 121.7331 & 78.9 & 121.7331 & 7.43594 & 511.4585 & 7.43594 \\
\hline Minimum & -40.47 & 0.0381 & 0.08363 & 0.38 & 0.08363 & 0.37105 & 4.489647 & 0.37105 \\
\hline Std. Dev. & 13.173 & 0.3102 & 24.48723 & 13.4183 & 24.48723 & 1.438195 & 107.9503 & 1.438195 \\
\hline Skewness & -0.37253 & 0.8103 & 1.861627 & -0.225505 & 1.861627 & 2.499982 & -1.508621 & 2.499982 \\
\hline Kurtosis & 5.361412 & 0.3812 & 6.284153 & 5.361412 & 6.284153 & 8.215936 & 4.435162 & 8.215936 \\
\hline Jarque-Bera & 84.9473 & 43.523 & 180.754 & 84.9473 & 180.754 & 382.8412 & 81.86523 & 382.8412 \\
\hline Probability & 0.1924 & 0.1749 & 0.0000 & 0.1924 & 0.0000 & 0.0000 & 0.0168 & 0.0000 \\
\hline Sum & 2688.97 & 1742.10 & 3798.604 & 2688.97 & 3798.604 & 331.3429 & 12738.18 & 331.3429 \\
\hline Sum Sq. Dev. & 31508.88 & 2841.90 & 104934.3 & 31508.88 & 104934.3 & 361.9711 & 2039323 & 361.9711 \\
\hline Observations & 176 & 176 & 176 & 176 & 176 & 176 & 176 & 176 \\
\hline
\end{tabular}

Table-3. Correlation Matrix.

\begin{tabular}{c|c|c|c|c|c|c|c|c}
\hline Variables & EST & FIN & POV & INS & EDU & URB & TOP & ESD \\
\hline EST & 1 & & & & & & & \\
\hline FIN & 0.02765 & 1 & & & & & & \\
\hline POV & -0.13224 & -0.06313 & 1 & & & & & \\
\hline INS & 0.207613 & 0.024357 & -0.29576 & 1 & & & & \\
\hline EDU & 0.06463 & 0.233936 & 0.023083 & -0.14467 & 1 & & & \\
\hline URB & -0.20761 & 0.024357 & -0.29576 & 0.03432 & 0.3286 & 1 & & \\
\hline TOP & 0.06463 & 0.233936 & 0.023083 & -0.14467 & 0.6532 & 0.5432 & 1 & \\
\hline ESD & 0.3201 & 0.4621 & 0.9407 & 0.64301 & 0.4593 & 0.9482 & 0.4588 & 1 \\
\hline
\end{tabular}




\begin{tabular}{|c|c|c|c|c|c|c|}
\hline Variables & $\begin{array}{l}\text { Levin } \\
\text { Level }\end{array}$ & $\begin{array}{c}\text { First } \\
\text { Difference }\end{array}$ & $\begin{array}{l}\text { Hadri } \\
\text { Level }\end{array}$ & $\begin{array}{c}\text { First } \\
\text { Difference }\end{array}$ & $\begin{array}{c}\text { Order of } \\
\text { Integration }\end{array}$ & Autocorrelation \\
\hline $\mathrm{EST}$ & $4.1733^{* * * *}$ & $10.6220^{*}$ & $9.2497 *$ & 1.7418 & $I(1)$ & No \\
\hline ESD & 1.220 .321 & $9.09250^{*}$ & 8.5012 & $0.4473^{* *}$ & $I(1)$ & No \\
\hline FIN & $3.1092^{* *}$ & 3.7987 & $13.7611^{* * * *}$ & 0.8540 & $I(1)$ & No \\
\hline POV & $-4.1733^{* * * *}$ & $-10.6220^{*}$ & $-9.2497^{*}$ & -1.7418 & $I(1)$ & No \\
\hline INS & $3.1092 * *$ & 3.7987 & $-13.7611^{* * * *}$ & 0.8540 & $I(1)$ & No \\
\hline EDU & 20.321 & $21.0925^{* * * *}$ & 11.5012 & $0.7046^{* *}$ & $I(1)$ & No \\
\hline $\mathrm{URB}$ & $-2.5662 * * *$ & -3.8131 & $-7.7809 * * *$ & -2.7355 & $I(1)$ & No \\
\hline TOP & 1.9064 & $0.0283^{* * * *}$ & 15.2917 & $2.3223^{*}$ & $I(O)$ & No \\
\hline
\end{tabular}

Table-5. Result of Lag length selection Criterions.

\begin{tabular}{c|c|c|c|c|c|c}
\hline Lag & LogL & LR & FPE & AIC & SC & HQ \\
\hline 0 & -3458.71 & NA & $1.69 \mathrm{E}+11$ & 40.04288 & 40.13402 & 40.07985 \\
\hline 1 & -2932.18 & 1016.529 & $5.13 \mathrm{E}+08$ & 34.2449 & $34.79171^{*}$ & 34.46674 \\
\hline 2 & -2868.26 & 119.7155 & $3.27 \mathrm{E}+08$ & 33.79493 & 34.79743 & $34.20164^{*}$ \\
\hline 3 & -2842.44 & $46.86218^{*}$ & $3.25 \mathrm{e}+08^{*}$ & $33.78547^{*}$ & 35.24364 & 34.37704 \\
\hline
\end{tabular}

Note: *indicates lag order selected by the criterion

LR: sequential modified LR test statistic (each test at $5 \%$ level)

FPE: Final prediction error.

AIC: Akaike information criterion.

SC: Schwarz information criterion.

HQ: Hannan-Quinn information criterion.

The study adopted Levin-Lin-Chu and Hadri tests to test for the presence of the unit roots in the panel data, Table 4. The results disclosed that the variables adopted for the study. The autocorrelation from results from Table 4 shows no serial autocorrelation problem among the variables used for the study.

To determine the appropriate lag length to be used for the study, we adopted lag selection used the VAR for the variable in levels for the analysis adopted by Akalpler and Hove (2019). The results presented in Table 5 show that all the lag selection criterions including sequential modified LR test statistic (LR), Final prediction error (FPE), and the Akaike's Information Criterion (AIC) suggest lag 3 for the study.

\begin{tabular}{c|c|c|c|c|c|c|c}
\multicolumn{1}{c}{ Table-6. Wald test. } \\
\hline Variable & ESD & EST & FIN & POV & INS & EDU & URB \\
\hline Value & 1.46123 & 1.6404 & 3.60505 & 18.31570 & 5.14551 & 18.31570 & 5.14551 \\
\hline P-values & 0.001 & 0.009 & 0.049 & 0.0081 & 0.026 & 0.0081 & 0.0163 \\
\hline
\end{tabular}

Table 6 presents the Wald Test framework in Eviews 10. We restricted the respective coefficients of the independent variables to zero after running the ordinary least square regression. The Wald test statistics, presented in table 6 show statistically significant contributions of EST, ESD, FIN, POV, INS, URB and TOP to the model so all the variables were adopted for the study.

Table-7. Results of model analysis of effect of explanatory variables of environmental sustainability (EST).

\begin{tabular}{|c|c|c|c|c|}
\hline Variables & DOLS & 2SLS & GMM & Fixed Effect \\
\hline \multirow[t]{2}{*}{ Constant } & $1.2609 * *$ & $1.0238^{* * *}$ & $1.5107 * *$ & $2.3484 * *$ \\
\hline & $(0.0378)$ & $(0.0285)$ & $(0.0279)$ & $(0.0465)$ \\
\hline \multirow[t]{2}{*}{ FIN } & 0.6278 & -0.5400 & 0.5816 & 0.6037 \\
\hline & $(0.0689)$ & $(0.0759)$ & $(0.0652)$ & $(0.0859)$ \\
\hline \multirow[t]{2}{*}{$\mathrm{POV}$} & $-0.5278^{*} *$ & $-0.6400^{*} *$ & $-0.2861 * *$ & $-0.4047 * *$ \\
\hline & $(0.0289)$ & $(0.0415)$ & $(0.0495)$ & $(0.0379)$ \\
\hline \multirow[t]{2}{*}{ INS } & $0.2804^{* *}$ & $0.1843^{* * *}$ & $0.0505^{* *}$ & $0.0908^{* * *}$ \\
\hline & $(0.0040)$ & $(0.0395)$ & $(0.0073)$ & $(0.0218)$ \\
\hline \multirow[t]{2}{*}{ EDU } & 0.3263 & 0.7600 & 0.3789 & 0.7559 \\
\hline & $(0.1297)$ & $(0.9231)$ & $(0.0635)$ & (0.0559) \\
\hline \multirow[t]{2}{*}{ URB } & $-0.0275^{*}$ & $-0.0356^{*}$ & $-0.0045^{*}$ & $-0.0143^{*}$ \\
\hline & $(0.0058)$ & $(0.0017)$ & $(0.0092)$ & $(0.0383)$ \\
\hline TOP & $\begin{array}{l}0.0275^{*} \\
(0.0058)\end{array}$ & $\begin{array}{l}0.0356^{*} \\
(0.0017)\end{array}$ & $\begin{array}{l}0.0045^{*} \\
(0.0092)\end{array}$ & $\begin{array}{l}0.0143^{*} \\
(0.0383)\end{array}$ \\
\hline $\mathrm{R}^{2}$ & 0.6775 & 0.7983 & 0.7337 & 0.8746 \\
\hline F-test & $\begin{array}{c}F=11.65 \\
(0.0000)\end{array}$ & $\begin{array}{l}F=11.13 \\
(0.0000)\end{array}$ & $\begin{array}{l}F=10.76 \\
(0.0000)\end{array}$ & $\begin{array}{l}\mathrm{F}=10.43 \\
(0.0000)\end{array}$ \\
\hline DW-Stat & 2.102 & 2.053 & 2.0431 & 2.0183 \\
\hline J-B-Stat (Normality) & $\begin{array}{c}0.738 \\
(0.262) \\
\end{array}$ & $\begin{array}{c}0.539 \\
(0.247)\end{array}$ & $0.722(0.573)$ & $0.705(0.602)$ \\
\hline Breusch Pagan LM test & $\begin{array}{c}\chi^{2}=0.052 \\
(0.5533)\end{array}$ & $\begin{array}{l}\chi^{2}=0.047 \\
(0.5021)\end{array}$ & $\begin{array}{c}\chi^{2}=0.054 \\
(0.5532)\end{array}$ & $\begin{array}{c}\chi^{2}=0.045 \\
(0.5092)\end{array}$ \\
\hline Hausman Test & $\begin{array}{c}\chi^{2}=18.42 \\
(0.0000)\end{array}$ & $\begin{array}{c}\chi^{2}=17.13 \\
(0.0000)\end{array}$ & $\begin{array}{l}\chi^{2}=17.77 \\
(0.0000)\end{array}$ & $\begin{array}{c}\chi^{2}=18.06 \\
(0.0000)\end{array}$ \\
\hline
\end{tabular}

Note: EST is dependent variable, given the results from the various tests conducted (F-test, DW-Stat, J-B-Stat, Breusch Pagan LM test and the Hausman Test); the fixed effects model has been chosen and consequently reported. *, ** means $5 \%$ and $1 \%$ significant levels respectively, and $\mathrm{t}$-values are reported in parenthesis. 


\subsection{Empirical Results}

Table 7 presents the results of the analysis conducted to determine the effect of explanatory factors on environmental sustainability (EST). All models affirm the positive effect of financial development on environmental sustainability. The table however reveals that the effect is stronger based on the DOLS model. This finding is consistent with the established position in the extant literature that economic growth is a major contributing factor to environmental sustainability.

Significantly, the association between poverty and environmental sustainability is negative. This implies that an exacerbating level of poverty has the potential to mutilate gains made in environmental sustainability. This observation is the most important in the case of this study that seeks to affirm the importance of reducing poverty to support environmental quality agenda. The results of the other variables namely trade openness, education and institutional quality returned a positive association with environmental sustainability. When these attributes are high in a country or region, it promotes environmentally responsible behaviours. Regarding the impact of urbanisation, the table discloses similar expectation as a negative association exits between urbanisation This results is not surprising as they affirm previous findings (Hafeez et al., 2020) of regression of the effect of health expenditure on environmental sustainability.

\begin{tabular}{|c|c|c|c|c|}
\hline Variables & DOLS & 2SLS & DOLS & 2SOLS \\
\hline \multirow[t]{2}{*}{ Constant } & 1.3744 & 1.0955 & 1.5862 & 1.4189 \\
\hline & $(0.0412)$ & (0.0305) & (0.0293) & $(0.0479)$ \\
\hline \multirow[t]{2}{*}{ FIN } & 0.3056 & 0.1972 & 0.0530 & 0.0935 \\
\hline & $(0.0044)$ & $(0.0423)$ & $(0.0077)$ & $(0.0225)$ \\
\hline \multirow[t]{2}{*}{ POV } & -0.3557 & -0.8132 & -0.3978 & -0.7786 \\
\hline & $(0.1414)$ & $(0.9877)$ & (0.0667) & $(0.0576)$ \\
\hline \multirow[t]{2}{*}{ INS } & -0.0300 & -0.0381 & -0.0047 & -0.0147 \\
\hline & (0.0063) & $(0.0018)$ & (0.0097) & $(0.0394)$ \\
\hline \multirow[t]{2}{*}{ EDU } & -0.5659 & -0.6838 & -0.0431 & -0.0082 \\
\hline & $(0.0471)$ & $(0.0524)$ & $(0.0076)$ & $(0.0187)$ \\
\hline \multirow[t]{2}{*}{ URB } & -0.0427 & -0.0419 & -0.0412 & -0.1997 \\
\hline & $(0.0485)$ & $(0.0476)$ & (0.0467) & $(0.0897)$ \\
\hline \multirow[t]{2}{*}{ TOP } & -0.1758 & 0.2173 & -0.2220 & -0.1731 \\
\hline & $(1.0110)$ & $(0.8960)$ & $(0.8542)$ & $(0.6921)$ \\
\hline $\mathrm{R}^{2}$ & 0.6775 & 0.7983 & 0.7337 & 0.8746 \\
\hline F-test & $\begin{array}{c}\mathrm{F}=11.65 \\
(0.0000)\end{array}$ & $\begin{array}{l}\mathrm{F}=11.13 \\
(0.0000)\end{array}$ & $\begin{array}{l}\mathrm{F}=10.76 \\
(0.0000)\end{array}$ & $\begin{array}{l}F=10.43 \\
(0.0000)\end{array}$ \\
\hline
\end{tabular}

Table 8 on the other hand presents the effect of the explanatory variables on the second measure of environmental sustainability (ESD). The results again confirm the previous findings in Table 7 regarding the effect of poverty on environmental sustainability. In this particular case, the analysis indicates that all the models confirms the existence of a negative influence of poverty on the improvement in environment.

Sustainable development remains an important issue in the quest to achieve a safe and a better world. The expansion of the 8 millennium development goals into the 17 sustainable development goals is a testament of the conscious desire to improve the human environment to ensure better quality of life for its citizens. To that extent the findings of this research adds to the stock of studies that attempts to unveil some of the key challenges that confronts todays and how they can be controlled. Specifically, the results of this study confirm the impact of poverty on both indicators of sustainable development. The results prove that poverty in sub-Saharan Africa is a threat to environmental quality and its consequential challenges. This therefore calls for the need to promote sustainable development. Previous findings have attested to the fact that strong financial development is necessary to enhance sustainable development. Additionally, the idea that good institutional and governance quality as well as education are important factors that can affect the sustainability war in Africa have all been affirmed in the findings of this research. There is an inalienable responsibility on the part of African governments and their development partners to promote both formal and non-formal education at all levels to give its citizens the greater understanding of the challenges that unsustainable development can impose.

Fortunately Africa has been spared the challenges of urbanisation on sustainability with the slow pace of urbanisation in the region. That notwithstanding the evidence adduced in this research supports and reinforces the outcome of prior studies that increase urbanisation will invariably affect sustainability negatively. There is therefore the need for African countries to brace up with more sustainable urban development measures as the region increases its urbanisation drive with economic growth.

Most importantly, this paper explored the effect of poverty on the environmental sustainability in sub-Saharan Africa. This result reflects earlier findings and suggestions made in the extant literature. In the works of Ansari, Haider, and Khan (2020); Pirgaip, Ertuğrul, and Ulussever (2021) they contend that while mankind, in general, places stress on the environment, poverty in particular has played a major role in environmental sustainability across the world. The results of this paper support this position. The analysis indicates that a unit increase in poverty corresponds to a massive decline in environmental sustainability. This places the burden to promote environmental sustainability equally at the door step of African leaders and private sector activities whose responsibility it is to support poverty eradication in Africa. Again the results give evidence to assert that private sector participation can significantly promote environmental sustainability. This is supported by the fact that financial development which was proxy by percentage of private sector share of GDP improves sustainability

Previous studies provide several ways by which sub-Saharan economies can improve poverty reduction to enhance sustainable development. The study notes that poverty is one of the strongest factors that affect environmental sustainability. This observation is not a contradiction to the well-established fact that prosperity or economic growth is a major precursor of unsustainable environment. On the contrary the evidence in this paper 
amplifies a consequence of a social crisis if they fester at both ends. In one breath, whereas economic growth or economic prosperity can compromise the quality of the environment, in like manner can abject poverty also reduce the quality of environment through environmentally irresponsible behaviors. This result implies that African countries in their pursuit of economic growth, education and effective healthcare to ameliorate poverty must incorporate other aggressive strategies to hasten poverty reduction.

According to Fan, Zhang, and Zhang (2002), poverty problem can be better solved through welfare redistribution but few developing countries have been able to reduce poverty through direct income transfer. For example, promoting income-generation capacity of the poor through effective public spending policy can lead to poverty alleviation and reduction in inequality among the poor. This will help them to alter their methods of production which can effectively stimulate pro-environmental behaviours. In other areas where aggressive poverty reduction strategy has already been initiated, this study calls for greater support to consolidate the gains made. For example, according to Mensah and Benedict (2010) entrepreneurship training has reduced poverty alleviation through the empowerment of the poorer people in the Eastern Free State of South Africa. This effectiveness of this policy is further demonstrated in Kolade (2018) who noted that entrepreneurship education (EE) intervention in Nigeria is transforming lives of poor communities. This is because such EE programme generates awareness and facilitates skills development, which has consequential effect on poverty reduction. The long-term effect is enhanced environmentally responsible behaviours of the beneficiaries. Thus, the findings of this research support the established view that the path to environmental sustainability is not through slower economic growth but rather through slower poverty levels.

\section{Conclusion}

The objective of this study was to examine the relationship between poverty and environmental sustainability in sub-Saharan Africa. Previous findings have shown the environmental pollution is associated with higher economic growth. Thus, rich countries are believed to pollute the environment more than poor countries. The findings of this research however disagree with this notion. On the contrary the findings reveal that poverty is also associated with high levels of pollution and poor countries including countries in sub-Saharan Africa contributes to reduction in sustainability in its two folds as used in this study. While the finding of this research is important contribution to the subject, there are some limitations. Firstly, the measurement of environmental sustainability takes many forms. This study adopted just two definitions of sustainability and that limits the concept of sustainability in this research. Moreover, the measurement of education, urbanisation, financial development, institutional quality and trade openness has all been measured by many different indicants. These varying differences in measurement limits the extent to which the generalisability of the findings of this research. Future research should compare the case in Sub-Saharan African with emerging economies especially the BRICS to better appreciate the development gap in terms of how different factors affect environment especially poverty.

\section{References}

Adedoyin, F. F., Alola, A. A., \& Bekun, F. V. (2020). An assessment of environmental sustainability corridor: The role of economic expansion and research and development in EU countries. Science of the Total Environment, 713, 136726. Available at: https://doi.org/10.1016/j.scitotenv.2020.136726.

Adekunle, I. A. (2020). On the search for environmental sustainability in Africa: On the search for environmental sustainability in Africa: The role of governance. Environmental Science and Pollution Research, 28(12), 14607-14620.

Adeyeye, S. A. O., Adebayo-Oyetoro, A. O., \& Tiamiyu, H. K. (2017). Poverty and malnutrition in Africa: a conceptual analysis. Nutrition $\mathbb{E}^{\circ}$ Food Science, 47(6), 754-764. Available at: https://doi.org/10.1108/NFS-02-2017-0027.

Akalpler, E., \& Hove, S. (2019). Carbon emissions, energy use, real GDP per capita and trade matrix in the Indian economy-an ARDL approach. Energy, 168, 1081-1093. Available at: https://doi.org/10.1016/j.energy.2018.12.012.

Ansari, M. A., Haider, S., \& Khan, N. (2020). Environmental Kuznets curve revisited: An analysis using ecological and material footprint. Ecological Indicators, 115, 106416. Available at: https://doi.org/10.1016/j.ecolind.2020.106416.

Arellano, M. (2003). Modelling optimal instrumental variables for dynamic panel data models (Vol. 310, pp. 443-450). Madrid: CEMFI.

Arrow, K. J., Dasgupta, P., Goulder, L. H., Mumford, K. J., \& Oleson, K. (2012). Sustainability and the measurement of wealth. Environment and Development Economics, 17(3), 317-353.

Asongu, S. A., Agboola, M. O., Alola, A. A., \& Bekun, F. V. (2020). The criticality of growth, urbanization, electricity and fossil fuel consumption to environment sustainability in Africa. Science of the Total Environment, 712, 136376. Available at: https://doi.org/10.1016/j.scitotenv.2019.136376.

Asongu, S. A., \& Odhiambo, N. M. (2021). Enhancing governance for environmental sustainability in sub-Saharan Africa. Energy Exploration E Exploitation, 39(1), 444-463. Available at: https://doi.org/10.1177/0144598719900657.

Aust, V., Morais, A. I., \& Pinto, I. (2020). How does foreign direct investment contribute to Sustainable Development Goals? Evidence from African countries. Journal of Cleaner Production, 245, 118823. Available at: https://doi.org/10.1016/j.jclepro.2019.118823.

Baloch, M. A., Khan, S. U.-D., \& Ulucak, Z. Ş. (2020). Poverty and vulnerability of environmental degradation in Sub-Saharan African countries: What causes what? Structural Change and Economic Dynamics, 54, 143-149. Available at: https://doi.org/10.1016/j.strueco.2020.04.007.

Baloch, M. A., Khan, S. U.-D., Ulucak, Z. Ş., \& Ahmad, A. (2020). Analyzing the relationship between poverty, income inequality, and CO2 emission in Sub-Saharan African countries. Science of the Total Environment, 740, 139867. Available at: https://doi.org/10.1016/j.scitotenv.2020.139867.

Bekun, F. V., Yalçiner, K., Etokakpan, M. U., \& Alola, A. A. (2020). Renewed evidence of environmental sustainability from globalization and energy consumption over economic growth in China. Environmental Science and Pollution Research, 27(23), 29644-29658. Available at: https://doi.org/10.1007/s1 1356-020-08866-2.

Blum, M., Ducoing, C., \& McLaughlin, E. (2017). A sustainable century? National Wealth: What is Missing, Why it Matters, 89-1 13.

Blundell, R., \& Bond, S. (1998). Initial conditions and moment restrictions in dynamic panel data models. Journal of Econometrics, 87(1), 115143. Available at: https://doi.org/10.1016/s0304-4076(98)00009-8.

Demissew Beyene, S., \& Kotosz, B. (2020). Testing the environmental Kuznets curve hypothesis: an empirical study for East African countries. International Journal of Environmental Studies, 77(4), 636-654. Available at: https://doi.org/10.1080/00207233.2019.1695445.

Dumitrescu, E.-I., \& Hurlin, C. (2012). Testing for Granger non-causality in heterogeneous panels. Economic Modelling, 29(4), 1450-1460. Available at: https://doi.org/10.1016/j.econmod.2012.02.014.

Edrees, A. (2015). Foreign direct investment, business environment and economic growth in Sub-Saharan Africa: Pooled mean group technique. Journal of Global Economics, 3, 144. Available at: https://doi.org/10.4172/2375-4389.1000144. 
Eluwole, K. K., Saint Akadiri, S., Alola, A. A., \& Etokakpan, M. U. (2020). Does the interaction between growth determinants a drive for global environmental sustainability? Evidence from world top 10 pollutant emissions countries. Science of the Total Environment, 705, 135972. Available at: https://doi.org/10.1016/j.scitotenv.2019.135972.

Fan, S., Zhang, L., \& Zhang, X. (2002). Growth, inequality, and poverty in rural China: The role of public investments (Vol. 125): International Food Policy Research Institute.

Fombad, M. (2018). Knowledge management for poverty eradication: A South African perspective. Journal of Information, Communication and Ethics in Society, $16(2)$, 193-213. Available at: https://doi.org/10.1108/JICES-04-2017-0022.

Greasley, D., Hanley, N., Kunnas, J., McLaughlin, E., Oxley, L., \& Warde, P. (2014). Testing genuine savings as a forward-looking indicator of future well-being over the (very) long-run. Journal of Environmental Economics and Management, 67(2), 171-188. Available at: https://doi.org/10.1016/j.jeem.2013.12.001.

Hafeez, M., Yuan, C., Shah, W. U. H., Mahmood, M. T., Li, X., \& Iqbal, K. (2020). Evaluating the relationship among agriculture, energy demand, finance and environmental degradation in one belt and one road economies. Carbon Management, 11(2), 139-154. Available at: https://doi.org/10.1080/17583004.2020.1721974.

Hartwick, J. M. (1990). Natural resources, national accounting and economic depreciation. Journal of public Economics, 43(3), 291-304. Available at: https://doi.org/10.1016/0047-2727(90)90002-y.

Hirons, M. (2020). How the sustainable development Goals risk undermining efforts to address environmental and social issues in the smallscale mining sector. Environmental Science \& Policy, 114,321-328. Available at: https://doi.org/10.1016/j.envsci.2020.08.022.

Ibrahim, M. D., \& Alola, A. A. (2020). Integrated analysis of energy-economic development-environmental sustainability nexus: Case study of MENA countries. Science of the Total Environment, 737, 139768. Available at: https://doi.org/10.1016/j.scitotenv.2020.139768.

Jan, W. U., \& Shah, M. (2020). A panel analysis of trade gravity between Pakistan and South Asian Countries. Comparative Economic Research. Central and Eastern Europe, 23(4), 187-207. Available at: https://doi.org/10.18778/1508-2008.23.34.

Joshua, U., \& Bekun, F. V. (2020). The path to achieving environmental sustainability in South Africa: The role of coal consumption, economic expansion, pollutant emission, and total natural resources rent. Environmental Science and Pollution Research, 27(9), 94359443. Available at: https://doi.org/10.1007/s11356-019-07546-0.

Kakwani, N., Wagstaff, A., \& Van Doorslaer, E. (1997). Socioeconomic inequalities in health: Measurement, computation, and statistical inference. Journal of Econometrics, 77(1), 87-103. Available at: https://doi.org/10.1016/s0304-4076(96)01807-6.

Khan, S. A. R., Yu, Z., Sharif, A., \& Golpîra, H. (2020). Determinants of economic growth and environmental sustainability in South Asian Association for Regional Cooperation: Evidence from panel ARDL. Environmental Science and Pollution Research, 27(36), 4567545687. Available at: https://doi.org/10.1007/s 1 1356-020-10410-1.

Khan, S. A. R., Zhang, Y., Kumar, A., Zavadskas, E., \& Streimikiene, D. (2020). Measuring the impact of renewable energy, public health expenditure, logistics, and environmental performance on sustainable economic growth. Sustainable Development, 28(4), 833-843. Available at: https://doi.org/10.1002/sd.2034.

Kirikkaleli, D., \& Sowah, J. K. (2020). A wavelet coherence analysis: Nexus between urbanization and environmental sustainability. Environmental Science and Pollution Research, 27(24), 30295-30305. Available at: https://doi.org/10.1007/s11356-020-09305-y.

Kolade, O. (2018). Venturing under fire: Entrepreneurship education, venture creation, and poverty reduction in conflict-ridden Maiduguri, Nigeria. Education+ Training, 60(7/8), 749-766. Available at: https://doi.org/10.1108/et-08-2017-0124.

Lan, K. C. (2021). Economic structure and environmental Kuznets curve hypothesis: New evidence from economic complexity. Applied Economics Letters, 28(7), 612-616. Available at: https://doi.org/10.1080/13504851.2020.1767280.

Mensah, S.-A., \& Benedict, E. (2010). Entrepreneurship training and poverty alleviation. Management, 1(2), 138-163.

Mnini, P., \& Ramoroka, T. (2020). Challenges of ecotourism and poverty alleviation in South Africa. International Journal of Economics and Finance Studies, 12(2), 184-197.

Ntow-Gyamfi, M., Bokpin, G. A., Aboagye, A. Q., \& Ackah, C. G. (2020). Environmental sustainability and financial development in A frica; does institutional quality play any role? Development Studies Research, 7(1), 93-118. Available at: https://doi.org/10.1080/21665095.2020.1798261.

Oseni, I. O. (2016). Exchange rate volatility and private consumption in Sub-Saharan African countries: A system-GMM dynamic panel analysis. Future Business Journal, 2(2), 103-115. Available at: https://doi.org/10.1016/j.fbj.2016.05.004.

Pearce, D., \& Atkinson, G. (1998). The concept of sustainable development: An evaluation of its usefulness ten years after Brundtland. Swiss Journal of Political Economy and Statistics, 134, 251-270.

Pearce, D. W., \& Atkinson, G. D. (1993). Capital theory and the measurement of sustainable development: An indicator of "weak" sustainability. Ecological Economics, 8(2), 103-108. Available at: https://doi.org/10.1016/0921-8009(93)90039-9.

Pezzey, J. C. (2004). Exact measures of income in a hyperbolic economy. Environment and Development Economics, 9(4), 473-484. Available at: https://doi.org/10.1017/s1355770x04001470.

Pirgaip, B., Ertuğrul, H. M., \& Ulussever, T. (2021). Is portfolio diversification possible in integrated markets? Evidence from South Eastern Europe. Research in International Business and Finance, 56, 101384. Available at: https://doi.org/10.1016/j.ribaf.2021.101384.

Radosavljevic, S., Haider, L. J., Lade, S. J., \& Schlüter, M. (2020). Effective alleviation of rural poverty depends on the interplay between productivity, nutrients, water and soil quality. Ecological Economics, 169, 106494. Available at: https://doi.org/10.1016/j.ecolecon.2019.106494.

Stock, J. H., \& Watson, M. W. (1993). A simple estimator of cointegrating vectors in higher order integrated systems. Econometrica: Journal of the Econometric Society, 61(4), 783-820. Available at: https://doi.org/10.2307/2951763.

Ullah, S., Awan, M. S., \& ul Hasan, M. (2020). Environmental quality and health status: Dynamic ordinary least square estimation for developing Asian countries. Forman Journal of Economic Studies, 16(January-December), 153-180. Available at: https://doi.org/10.32368/fjes.20201607.

Usman, O., Akadiri, S. S., \& Adeshola, I. (2020). Role of renewable energy and globalization on ecological footprint in the USA: Implications for environmental sustainability. Environmental Science and Pollution Research, 27(24), 30681-30693. Available at: https://doi.org/10.1007/s 1 1356-020-09170-9.

World Bank, R. (2015). Poverty in a rising Africa. from the World Bank.

World Bank Report. (2018a). Poverty and shared prosperity from World Bank. Retrieved from https://www.worldbank.org/en/publication/poverty-and-shared-prosperity.

World Bank Report. (2018b). Year in review: 2018 in 14 Charts. from the World Bank. Retrieved from https://www.worldbank.org/en/news/feature/2018/12/21/year-in-review-2018-in-14-charts. 